\title{
Short communication: Processed bovine colostrum milk protein concentrate increases epithelial barrier integrity of Caco-2 cell layers
}

\author{
Rachel C. Anderson, ${ }^{1,2 *} \odot$ Julie E. Dalziel, ${ }^{1,2} \oplus$ Neill W. Haggarty, ${ }^{3}$ Kelly E. Dunstan, ${ }^{1}$ Pramod K. Gopal, ${ }^{2,3} \dagger$ \\ and Nicole C. Roy ${ }^{1,2,4}$ \\ ${ }^{1}$ Food Nutrition \& Health Team, AgResearch, Private Bag 11008, Palmerston North, 4442, New Zealand \\ ${ }^{2}$ Riddet Institute, Massey University, Private Bag 11222, Palmerston North 4410, New Zealand \\ ${ }^{3}$ Fonterra Research and Development Centre, Fonterra Co-Operative Group, Private Bag 11029, Palmerston North 4442, New Zealand \\ ${ }^{4}$ High-Value Nutrition National Science Challenge, Auckland, New Zealand
}

\section{ABSTRACT}

Colostrum plays an important role in initiating the development of the intestinal barrier in newborn mammals. Given its bioactivity, there is much interest in the potential use of bovine colostrum to improve human gastrointestinal health throughout the life span. There is evidence that bovine colostrum is effective at improving small intestinal barrier integrity and some indication that it may alter colonic motility. However, for colostrum to be used as a product to improve intestinal health, it needs to be bioactive after processing. The aim of this study was to determine whether industrial processing of bovine colostrum affects its ability to improve small intestinal barrier integrity or alter distal colon motility. Three colostrum sample types were compared; raw whole colostrum powder (WCP), raw skim colostrum powder (SCP), and industrially produced colostrum milk protein concentrate (CMPC). To determine whether these colostrum powders had different effects on small intestinal barrier integrity, their effects on the transepithelial electrical resistance across an in vitro intestinal epithelial layer (Caco-2 cells) were measured, both with and without a challenge from the proinflammatory cytokine tumor necrosis factor- $\alpha$. These results showed that CMPC enhanced transepithelial electrical resistance across unchallenged epithelial cell layers, whereas the raw colostrum samples, WCP and SCP, did not have an effect. The colostrum samples were also compared to determine how they affect contractility in the distal colon isolated from the rat. Skim colostrum powder was the only sample to act directly on colonic

Received May 12, 2019.

Accepted July 10, 2019.

*Corresponding author: rachel.anderson@agresearch.co.nz

$\dagger$ Current address: Food, Nutrition and Health Group, Plant and Food Research, Private Bag 11600, Palmerston North 4442, New Zealand. tissue to modulate motility, increasing the amplitude of contractions. The results show that bovine colostrum is able to improve small intestinal barrier integrity and alter colon motility, and they implicate different components. The barrier integrity enhancement was apparent only in the industrial CMPC, which may have been due to the increase in protein concentration or the release of small peptides as a result of processing. The ability to alter colon motility was present in SCP but absent in WCP, again implying that an increase in protein concentration is responsible for the effect. However, this effect was not apparent for the industrially processed CMPC, suggesting denaturation or degradation of the active component. The beneficial effect of colostrum on small intestinal barrier integrity was present after processing, confirming that it is feasible to industrially produce an active product for gut health.

Key words: raw colostrum, tight junction, motility, transit

\section{Short Communication}

Colostrum is the first food to enter the gastrointestinal tract of a newborn mammal, and as such it is thought to be important in stimulating the development of intestinal barrier function. Given its bioactivity, there is much interest in the potential use of bovine colostrum to improve human intestinal health throughout the life span (Rathe et al., 2014; Bagwe et al., 2015; Menchetti et al., 2016). There is evidence that bovine colostrum is effective at improving small intestinal barrier integrity. For example, bovine colostrum reduces heat-induced small intestinal permeability in rats (Prosser et al., 2004), small intestinal damage caused by nonsteroidal anti-inflammatory drug usage in rats (Kim et al., 2005) and humans (Playford et al., 2001), and hyperpermeability in athletes during peak training (Hałasa et al., 2017). Bovine colostrum supplementation is also known to reduce the incidence of diarrhea in children (Saad et al., 2016) and has been shown to induce adaptive 
changes within smooth muscle following small intestinal resection (Pereira-Fantini et al., 2008). These studies indicate that colostrum can slow down gastrointestinal transit; however, this has not specifically been studied previously.

In order for colostrum to be used to improve intestinal health, it needs to be bioactive after industrial processing. The aim of this study was to determine whether processing affects the ability of bovine colostrum to improve small intestinal barrier integrity or alter distal colon motility. Three colostrum sample types were compared: (1) whole colostrum powder (WCP), which was made by lyophilizing fresh, unpasteurized (raw) colostrum; (2) skim colostrum powder (SCP), which was made by removing the fat from fresh, unpasteurized (raw) colostrum using centrifugation and then lyophilizing; and (3) industrially produced colostrum milk protein concentrate (CMPC), which was prepared by ultrafiltration and spray-drying of pasteurized skim colostrum.

The macronutrient concentrations in the 3 types of colostrum samples (WCP, SCP, and CMPC) from season 1 (S1) and CMPC from season $2($ S2) were determined by the Nutrition Laboratory, Massey Institute of Food Science and Technology (Massey University, Palmerston North, New Zealand). The following techniques were used: CP, Leco total combustion method (AOAC International, 2016; method 968.06); lactose, enzymatic colorimetric; fat, acid hydrolysis/Mojonnier extraction (AOAC International, 2016; method 954.02); TS/moisture, vacuum oven (AOAC International, 2016; methods 990.19, 990.20); and ash, furnace at $550^{\circ} \mathrm{C}$ (AOAC International, 2016; method 942.05). The results are summarized in Table 1. As expected, SCP contained minimal fat and CMPC contained less lactose compared with WCP. The composition of the CMPC was similar between seasons, indicating that the industrial processing technique was consistent.

To determine whether these compositional differences and process techniques resulted in differences in effects on small intestinal barrier integrity, the transepithelial electrical resistance (TEER) across an in vitro epithelial layer was measured in response to the colostrum samples. The ability of the colostrum samples to overcome the decrease in TEER caused by the proinflammatory cytokine tumor necrosis factor- $\alpha(\mathbf{T N F} \boldsymbol{\alpha})$ was also investigated. Caco-2 cells were used as a model of the small intestinal epithelium because they differentiate into polarized epithelial cells with apical brush borders and intracellular tight junctions (Le Ferrec et al., 2001; Shah et al., 2006). Caco-2 cell stock cultures were maintained as previously described (Anderson et al., 2017). For the assays, Caco-2 cells were seeded in 6.5 -mm polyester Transwells inserts with $0.4-\mu \mathrm{m}$ membrane pore size (Corning Inc., Corning, NY) in 24-well plates at a concentration of $8 \times 10^{4}$ cells/Transwell and grown in Medium 199 (M199; Gibco, Life Technologies, Auckland, New Zealand) supplemented with $10 \%$ fetal bovine serum (FBS; Gibco, Life Technologies), $1 \%$ NEAA (MEM NEAA 100× solution, Sigma-Aldrich, St. Louis, MO), and $1 \%$ penicillin-streptomycin $(10,000$ units/mL penicillin $\mathrm{G}$ sodium salt and $10,000 \mu \mathrm{g} / \mathrm{mL}$ streptomycin sulfate in $0.85 \%$ saline; Gibco, Life Technologies) at $37^{\circ} \mathrm{C}$ in $5 \% \mathrm{CO}_{2}$ for 17 to $19 \mathrm{~d}$ until they formed a differentiated monolayer.

The day before the TEER assay, Transwells containing the Caco-2 cell monolayers were transferred into a cellZscope cell module (nanoAnalytics $\mathrm{GmbH}$, Münster, Germany), which is an automated system for measuring TEER over time (Wegener et al., 2004). The basal compartments were filled with M199 supplemented with $10 \%$ FBS, $1 \%$ NEAA, and $1 \%$ penicillin-streptomycin, and the apical compartments were filled with M199 supplemented with 1\% NEAA and 1\% penicillinstreptomycin. The FBS was not included in the apical compartment in case of interference with the protein ingredients. The cell module was placed in the incubator $\left(37^{\circ} \mathrm{C}, 5 \% \mathrm{CO}_{2}\right)$ and connected to the cellZscope controller (nanoAnalytics) and computer. The TEER across the cell layers was measured hourly for $24 \mathrm{~h}$ using the computer-controlled system. Caco- 2 monolayers with a baseline TEER greater than $400 \Omega / \mathrm{cm}^{2}$ were used for assays.

On the day of the assay, the apical medium was replaced with control medium (M199 supplemented with $1 \%$ NEAA and $1 \%$ penicillin-streptomycin) or $1 \mathrm{mg} /$

Table 1. Composition of colostrum samples used in this study and summary of the observed activity

\begin{tabular}{|c|c|c|c|c|c|c|c|c|}
\hline Name & Description & $\begin{array}{l}\text { Protein } \\
(\%)\end{array}$ & $\begin{array}{c}\text { Lactose } \\
(\%)\end{array}$ & $\begin{array}{l}\text { Fat } \\
(\%)\end{array}$ & $\begin{array}{c}\text { Moisture } \\
(\%)\end{array}$ & $\begin{array}{l}\text { Ash } \\
(\%)\end{array}$ & $\begin{array}{l}\text { Altered } \\
\text { TEER }^{1}\end{array}$ & $\begin{array}{l}\text { Altered } \\
\text { contractions }\end{array}$ \\
\hline WCP & Raw colostrum whole milk powder & 55.6 & 14.6 & 19.3 & 0.6 & 5.2 & No & No \\
\hline SCP & Raw colostrum skim milk powder & 67.2 & 16.0 & 0.7 & 3.9 & 6.2 & No & Yes \\
\hline CMPC (S1) & Commercial colostrum milk protein concentrate (season 1) & 79.4 & 6.2 & 1.7 & 4.0 & 5.5 & Yes & No \\
\hline CMPC (S2) & Commercial colostrum milk protein concentrate (season 2) & 80.9 & 6.3 & 1.6 & 3.6 & 5.6 & Yes & No \\
\hline
\end{tabular}

\footnotetext{
${ }^{1}$ Transepithelial electrical resistance.
} 
$\mathrm{mL}$ of the test sample in control medium. The basal medium was replaced with fresh M199 supplemented with 10\% FBS (unchallenged cells), 1\% NEAA, and 1\% penicillin-streptomycin or the same medium containing $100 \mathrm{ng} / \mathrm{mL} \mathrm{TNF} \alpha$ ( $\mathrm{TNF} \alpha$-challenged cells). The experiment was completed in 3 blocks with 4 replicates per treatment in each block $(\mathrm{n}=12$ per treatment). The TEER was measured every hour for $40 \mathrm{~h}$, and the change in TEER compared with the initial TEER for each cell layer was calculated. The change in TEER values was analyzed using $\mathrm{R}$ version 3.3.2 in RStudio version 1.0.136 (www.rstudio.com). Treatments were compared using repeated-measures ANOVA to take account of the fact that the same cell layers were measured over time. The analysis included the replicates nested within blocks. If the treatment $x$ time effect was significant $(P<0.05)$, individual treatments at a given time point were compared using the least significant difference at $5 \%$ method.

The results are given in Figure 1. For all treatments, there was an initial decrease in TEER due to the changing of the medium temporarily disturbing the cell layers. For cells treated with control medium, the TEER returned to the initial level over the first $6 \mathrm{~h}$, whereas for the cells treated with TNF $\alpha$, TEER stabilized at 40 to $50 \%$ less than the initial level, indicating that $\mathrm{TNF} \alpha$ had a detrimental effect on barrier integrity, as expected. For the season 1 test samples, there was a significant treatment $\times$ time effect for the unchallenged Caco-2 cell layers $(P<0.0001)$ and those challenged with TNFa $(P=0.018)$. Whole colostrum powder and SCP increased TEER relative to the control medium only during the first 2 to $3 \mathrm{~h}$ of recovery, whereas CMPC (S1) increased TEER relative to the control medium over a $10-\mathrm{h}$ period. The experiment was repeated with CMPC (S2); again, there was a significant treatment $\times$ time effect for the unchallenged Caco-2 cell layers $(P=0.015)$, but there was no difference in those challenged with TNF $\alpha=1)$. Colostrum milk protein concentrate (S2) increased TEER compared with the control medium from $12 \mathrm{~h}$ until the end of the experiment at $40 \mathrm{~h}$. In the presence of $\mathrm{TNF} \alpha, \mathrm{CMPC}$ (S1) increased TEER relative to the control medium but CMPC (S2) did not. This could indicate that there was a season variation in bioactivity, but given that the effect of CMPC (S1) was apparent only during the period of recovery after medium change, it is unlikely to be biologically relevant.

These results showed that the industrial colostrum product had an effect on TEER, whereas the raw colostrum samples did not. This implies that the active component is in the protein fraction of the colostrum because CMPC has a higher protein concentration and reduced fat and lactose concentrations compared with the other samples. To investigate this further, we could increase the concentration of WCP so that the protein concentration in the solution is the same as the protein concentration in the CMPC solution. However, this would also increase the lactose concentration, which is a concern because we have previously shown that high lactose concentration reduces TEER (Anderson et al., 2018), so it would likely mask any beneficial effects of the increase in protein.

We have previously shown that bovine milk caseins (our unpublished data) and whey protein concentrate (Dalziel et al., 2016) do not alter TEER. Therefore, the active component is likely a protein that is in a higher concentration in colostrum compared with standard milk, such as antimicrobials (e.g., lactoferrin), growth factors (e.g., IGF-1, IGF-2, and transforming growth factor- $\alpha$ ), and various immunoglobulins, particularly IgG (Pakkanen and Aalto, 1997). The active component is unlikely to be lactoferrin because we have shown that pure lactoferrin does not increase TEER under these same test conditions (Anderson et al., 2017), and others have shown that lactoferrin does not alter tight junction protein formation (Majka et al., 2016). Growth factors are known to retain activity during processing, so they may be TEER-enhancing components; however, additional work is required to test this. We cannot rule out the possibility that the industrial processing treatment altered protein structure, removed inhibitors, or released peptides via endogenous protease activity to provide a more bioactive form.

It also is possible that components in the lipid fraction have benefits for small intestinal barrier integrity (Chen-Quay et al., 2009). We have previously shown that bovine milk complex lipids improve measures of small intestinal barrier integrity, including TEER (Anderson et al., 2018). In the current study, the sample that contained colostrum lipids, WCP, also contained lactose, which is known to mask effects in the TEER assay (Anderson et al., 2018). Further research tests with a colostrum lipid fraction excluding lactose are needed to elucidate whether the lipids are active ingredients.

The 4 colostrum samples were also compared to determine how their different macronutrient compositions affect contractility in the distal colon isolated from the rat. Methods similar to those described previously for the short distal colon were used (Dalziel et al., 2013, 2014, 2015, 2016). After killing, a 4-cm piece of distal colon was removed $1 \mathrm{~cm}$ distal to the striations of the mid colon. The tissue was placed in Krebs buffer (118 $\mathrm{m} M \mathrm{NaCl}, 4.7 \mathrm{~m} M \mathrm{KCl}, 1.2 \mathrm{~m} M \mathrm{KH}_{2} \mathrm{PO}_{4}, 1.2 \mathrm{~m} M$ $\mathrm{MgSO}_{4}, 2.6 \mathrm{~m} M \mathrm{CaCl}_{2}, 25 \mathrm{~m} M \mathrm{NaHCO}_{3}$, and $11 \mathrm{mM}$ glucose; $\mathrm{pH} 7.4$ ) oxygenated with $95 \% \mathrm{O}_{2} / 5 \% \mathrm{CO}_{2}$. The 

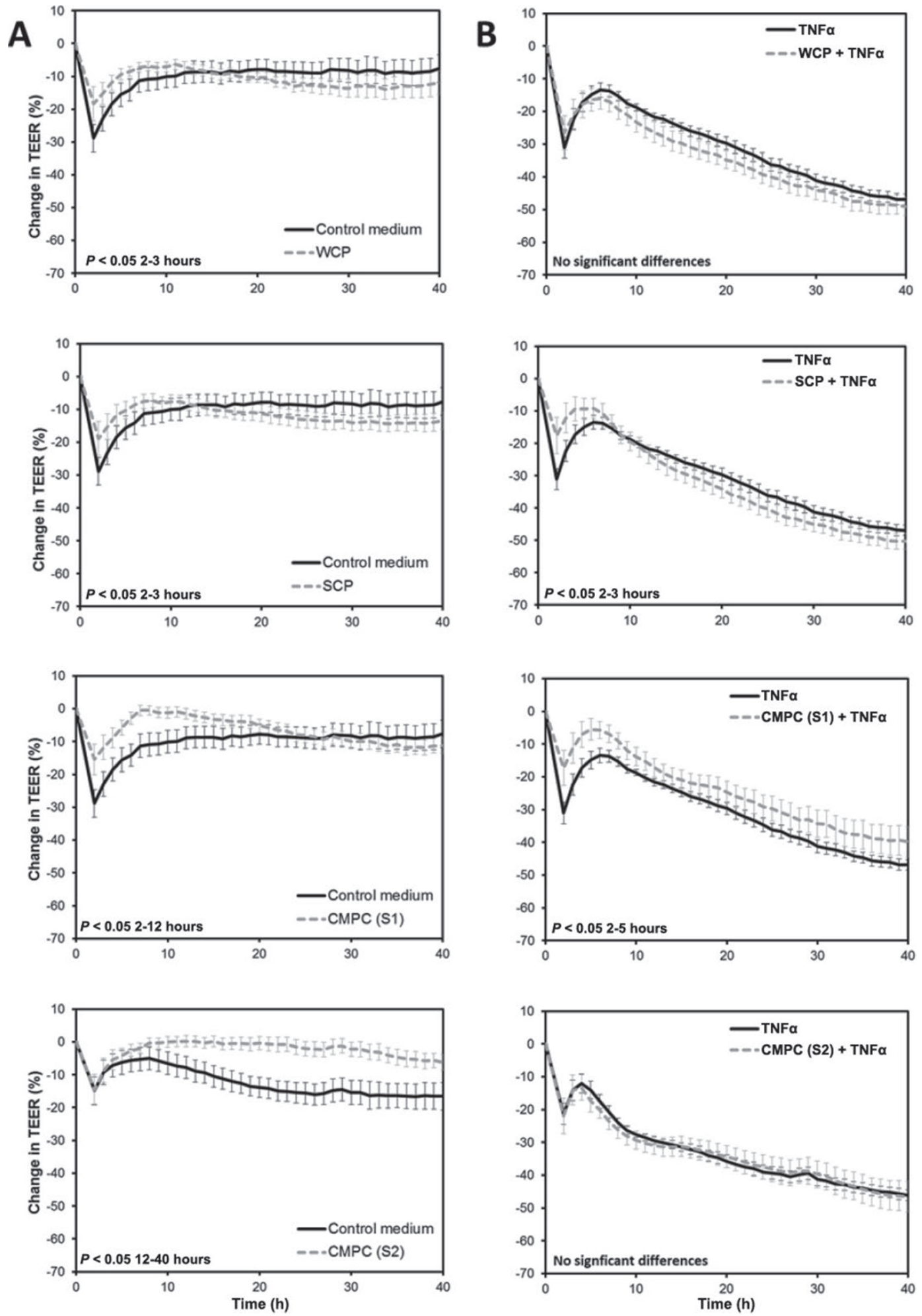

Figure 1. Effect of colostrum samples on the transepithelial electrical resistance (TEER) across Caco-2 cell monolayers (A) under normal conditions and $(\mathrm{B})$ challenged with tumor necrosis factor- $\alpha(\mathrm{TNF} \alpha)$. Data are from 3 blocks each with 4 replicates per treatment $($ total $\mathrm{n}=12$ per treatment). Values are means \pm SEM. $\mathrm{WCP}=$ raw colostrum whole milk powder; $\mathrm{SCP}=$ raw colostrum skim milk powder; CMPC (S1) $=$ commercial colostrum milk protein concentrate (season 1); CMPC (S2) = commercial colostrum milk protein concentrate (season 2). 
preparation was divided into 4 pieces of equal length, and each distal colon piece was mounted longitudinally on holders in an isolated tissue bath system (SI-MB4, SI-Heidelberg, World Precision Instruments, Sarasota, $\mathrm{FL})$ at $37^{\circ} \mathrm{C}$. Tissues were suspended under $2 \mathrm{~g}$ of tension and equilibrated for $1 \mathrm{~h}$ in Krebs buffer, during which time the bath solution was exchanged every 15 min. Spontaneous smooth muscle contractions vary among preparations in their amplitude and frequency. Control recordings were measured during the last 10 min of a 1-h exposure to Krebs buffer and compared with the last $10 \mathrm{~min}$ of the response to $15 \mathrm{~min}$ of exposure to the test treatments. Test treatments were added to the tissue preparation by bath perfusion. This mimics in vivo exposure following absorption from the small intestine and reaching the colon via the circulatory system. Smooth muscle contraction data were measured using BAM21-E amplifiers integrated using Lab-Trax 4/24T hardware and acquired and analyzed using Labscribe 2 software (iWorx Inc., Dover, NH). To allow for recovery from the effect of the treatment, solution exchange with Krebs buffer was carried out 3 times over 45 min. Contractile amplitude (g) was measured from the baseline to the maximum peak of the contractile amplitude response. Contractile frequency was measured as the number of contractions counted per minute. The mean for contractile amplitude or frequency was determined from the contractile responses recorded over $10 \mathrm{~min}$.

The response variables amplitude and frequency were normalized within each animal to take into account the variability between animals. Ratios for each time point after the treatment had been applied were calculated by dividing the amplitude or frequency by the value at the initial time point. The ratio was log-transformed to meet the requirements of ANOVA. Data were analyzed in GenStat version 18 (VSN International Ltd., Hemel Hempstead, UK) using a 2-way ANOVA to examine the effects of the factors treatment and time. The Studentized maximum modulus confidence intervals of the ratios at each time point for each treatment were examined. If the confidence intervals included zero, then the response was not significantly different from the value at time 0 .

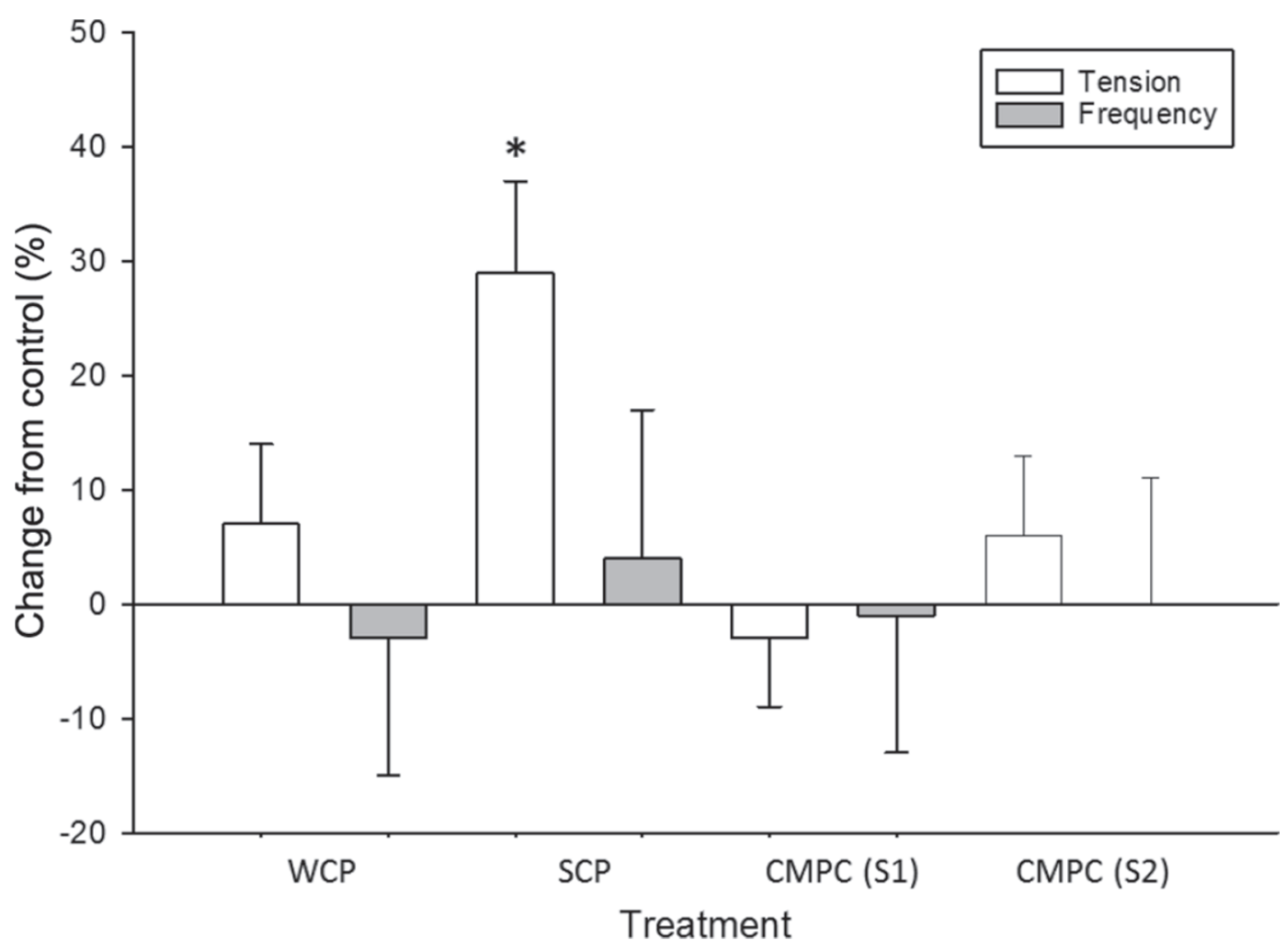

Figure 2. Effect of bovine colostrum samples on the contractile response in the rat distal colon. The effect of $1 \mathrm{mg} / \mathrm{mL}$ on contractile tension and frequency is shown as a percentage of the pretreatment control, where treatments were applied to separate preparations, averaged over the preceding $10 \mathrm{~min}$ of a 15 -min application $(\mathrm{n}=10-13$ per treatment $)$. $\mathrm{WCP}=$ raw colostrum whole milk powder; $\mathrm{SCP}=$ raw colostrum skim milk powder; CMPC (S1) = commercial colostrum milk protein concentrate (season 1); CMPC (S2) = commercial colostrum milk protein concentrate (season 2). Data show mean \pm SEM. Asterisk indicates significance difference $\left({ }^{*} P<0.05\right)$. 
A summary of the results is given in Figure 2. Skim colostrum powder significantly increased the amplitude of contractions but did not affect the frequency $(P<0.05)$. These results indicate that SCP was able to act directly on colonic tissue to modulate motility. No effect of the other ingredients on colonic motility was detected. The difference between the 2 lyophilized colostrum samples is that the majority of the lipids were removed from SCP compared with WCP, which in turn increased protein concentration by $21 \%$. This may have provided a higher concentration of a modulatory peptide.

If the active ingredient was a peptide in SCP, then the lack of effect of the industrial colostrum samples, which have an even higher protein concentration than SCP, might be due to loss or degradation during skimming, pasteurization, ultrafiltration, and spray drying. We cannot rule out involvement of a hormone elevated in colostrum such as progesterone that is heat sensitive (Falconer et al., 2014) and known to alter gastrointestinal motility (Baumgartner et al., 2017) and transit (Liu et al., 2002) in rats. However, because the predominant effect occurred with skim milk powder rather than whole milk, this implicates a protein-derived component as the active colonic motility-modulating ingredient.

The results show that some bovine colostrum samples were able to improve small intestinal barrier integrity and alter colon motility. The ability to enhance barrier integrity was apparent only in the industrially processed colostrum. This may have been due to the increase in protein concentration or the release of small peptides, but further work is required to assess this. In contrast, the ability to alter colon motility was seen only with lyophilized SCP, indicating that denaturation or degradation of the active component during processing may have occurred. These results imply that the components in colostrum responsible for affecting barrier integrity and motility are different. The beneficial effect of colostrum on small intestinal barrier integrity was present in processed colostrum, confirming that it is feasible to industrially produce an active product for gut health.

\section{ACKNOWLEDGMENTS}

This research was funded by the New Zealand Ministry of Business, Innovation and Employment (Wellington, New Zealand; contract C10X1003, "Dairy-based solutions for improved intestinal function," and contract C10X1706, "Dairy products for smarter lives"). We thank Leigh Ryan (AgResearch, Palmerston North, New Zealand) for technical assistance with the transepithelial electrical resistance and Catherine McKen- zie (AgResearch, Palmerston North, New Zealand) for statistical analysis.

\section{REFERENCES}

Anderson, R. C., S. A. Bassett, N. W. Haggarty, P. K. Gopal, K. M. Armstrong, and N. C. Roy. 2017. Short communication: Earlylactation, but not mid-lactation, bovine lactoferrin preparation increases epithelial barrier integrity of Caco-2 cell layers. J. Dairy Sci. 100:886-891.

Anderson, R. C., A. K. H. MacGibbon, N. Haggarty, K. M. Armstrong, and N. C. Roy. 2018. Bovine dairy complex lipids improve in vitro measures of small intestinal epithelial barrier integrity. PLoS One 13:e0190839.

AOAC International. 2016. Official Methods of Analysis. 20th ed. AOAC International. Gaithersburg, MD.

Bagwe, S., L. J. Tharappel, G. Kaur, and H. S. Buttar. 2015. Bovine colostrum: An emerging nutraceutical. J. Complement. Integr. Med. 12:175-185.

Baumgartner, C., T. Hubacher, M. Krayer, and J. Gschossmann. 2017. In vitro spontaneous contractile activity of colonic smooth muscle in naive Lewis rats: Acute effect of gonadal hormones. J. Dig. Dis. 18:13-22.

Chen-Quay, S. C., K. T. Eiting, A. W. A. Li, N. Lamharzi, and S. C. Quay. 2009. Identification of tight junction modulating lipids. J. Pharm. Sci. 98:606-619.

Dalziel, J. E., R. C. Anderson, S. A. Bassett, C. M. Lloyd-West, N. W. Haggarty, and N. C. Roy. 2016. Influence of bovine whey protein concentrate and hydrolysate preparation methods on motility in the isolated rat distal colon. Nutrients 8:E809.

Dalziel, J. E., K. E. Dunstan, and S. C. Finch. 2013. Combined effects of fungal alkaloids on intestinal motility in an in vitro rat model. J. Anim. Sci. 91:5177-5182.

Dalziel, J. E., V. Mohan, J. Peters, R. C. Anderson, P. K. Gopal, and N. C. Roy. 2015. The probiotic Escherichia coli Nissle 1917 inhibits propagating colonic contractions in the rat isolated large intestine. Food Funct. 6:257-264.

Dalziel, J. E., N. J. Spencer, K. E. Dunstan, A. T. Lynch, N. W. Haggarty, P. K. Gopal, and N. C. Roy. 2014. An in vitro rat model of colonic motility to determine the effect of $\beta$-casomorphin- 5 on propagating contractions. Food Funct. 5:2768-2774.

Falconer, J. R., J. Wen, S. Zargar-Shoshtari, J. J. Chen, M. Farid, S. J. Tallon, and R. G. Alany. 2014. Preparation and characterization of progesterone dispersions using supercritical carbon dioxide. Drug Dev. Ind. Pharm. 40:458-469.

Hałasa, M., D. Maciejewska, M. Baśkiewicz-Hałasa, B. Machaliński, K. Safranow, and E. Stachowska. 2017. Oral supplementation with bovine colostrum decreases intestinal permeability and stool concentrations of zonulin in athletes. Nutrients 9:E370.

Kim, J. W., W. K. Jeon, J. W. Yun, D. I. Park, Y. K. Cho, I. K. Sung, C. I. Sohn, B. I. Kim, J. S. Yeom, H. S. Park, E. J. Kim, and M. S. Shin. 2005. Protective effects of bovine colostrum on non-steroidal anti-inflammatory drug induced intestinal damage in rats. Asia Pac. J. Clin. Nutr. 14:103-107.

Le Ferrec, E., C. Chesne, P. Artusson, D. Brayden, G. Fabre, P. Gires, F. Guillou, M. Rousset, W. Rubas, and M. L. Scarino. 2001. In vitro models of the intestinal barrier. The report and recommendations of ECVAM Workshop 46. European Centre for the Validation of Alternative Methods. Altern. Lab. Anim. 29:649-668.

Liu, C.-Y., L.-B. Chen, P.-Y. Liu, D.-P. Xie, and P. S. Wang. 2002. Effects of progesterone on gastric emptying and intestinal transit in male rats. World J. Gastroenterol. 8:338-341.

Majka, G., G. Więcek, M. Śróttek, K. Śpiewak, M. Brindell, J. Koziel, J. Marcinkiewicz, and M. Strus. 2016. The impact of lactoferrin with different levels of metal saturation on the intestinal epithelial barrier function and mucosal inflammation. Biometals 29:10191033.

Menchetti, L., G. Traina, G. Tomasello, P. Casagrande-Proietti, L. Leonardi, O. Barbato, and G. Brecchia. 2016. Potential benefits of 
colostrum in gastrointestinal diseases. Front. Biosci. (Schol. Ed.) 8:331-351.

Pakkanen, R., and J. Aalto. 1997. Growth factors and antimicrobial factors of bovine colostrum. Int. Dairy J. 7:285-297.

Pereira-Fantini, P. M., S. L. Thomas, R. G. Taylor, E. Nagy, M. Sourial, P. J. Fuller, and J. E. Bines. 2008. Colostrum supplementation restores insulin-like growth factor-1 levels and alters muscle morphology following massive small bowel resection. J. Parenter. Enteral Nutr. 32:266-275.

Playford, R. J., C. E. MacDonals, D. P. Calnon, D. N. Floyd, T. Podas, W. Johnson, A. C. Wicks, O. Bashir, and T. Marchbank. 2001. Coadministration of the health food supplement, bovine colostrum, reduces the acute non-steroidal anti-inflammatory drug-induced increase in intestinal permeability. Clin. Sci. (Lond.) 100:627-633.

Prosser, C., K. Stelwagen, R. Cummins, P. Guerin, N. Gill, and C. Milne. 2004. Reduction in heat-induced gastrointestinal hyperpermeability in rats by bovine colostrum and goat milk powders. J. Appl. Physiol. 96:650-654.

Rathe, M., K. Müller, P. T. Sangild, and S. Husby. 2014. Clinical applications of bovine colostrum therapy: A systematic review. Nutr. Rev. 72:237-254.
Saad, K., M. G. Abo-Elela, K. A. El-Baseer, A. E. Ahmed, F. A Ahmad, M. S. Tawfeek, A. A. El-Houfey, M. D. AboulKhair, A. M. Abdel-Salam, A. Abo-Elgheit, H. Qubaisy, A. M. Ali, and E. Abdel-Mawgoud. 2016. Effects of bovine colostrum on recurrent respiratory tract infections and diarrhea in children. Medicine (Baltimore) 95:e4560.

Shah, P., V. Jogani, T. Bagchi, and A. Misra. 2006. Role of Caco-2 cell monolayers in prediction of intestinal drug absorption. Biotechnol. Prog. 22:186-198.

Wegener, J., D. Abrams, W. Willenbrink, H. J. Galla, and A. Janshoff. 2004. Automated multi-well device to measure transepithelial electrical resistances under physiological conditions. Biotechniques $37: 590-597$.

\section{ORCIDS}

Rachel C. Anderson ๑ https://orcid.org/0000-0003-2191-0655

Julie E. Dalziel ๑ https://orcid.org/0000-0003-3629-2351 